\title{
GENETIC ANALYSIS OF A RECENTLY DISCOVERED POPULATION OF THE LEAST CHUB (IOTICHTHYS PHLEGETHONTIS)
}

\author{
Karen E. Mock ${ }^{1,2}$ and Lee S. Bjerregaard ${ }^{1}$
}

Key words: least chub, Iotichthys, genetic diversity, population structure.

The least chub (Iotichthys phlegethontis) is a cyprinid minnow endemic to the Bonneville Basin of Utah. Although historically widely distributed in the Bonneville Basin (Sigler and Miller 1963, Page and Burr 1991, Muck 1999), naturally occurring populations of least chub are currently restricted to 6 populations in 4 general locations (Mona Springs, Mills Valley, Snake Valley, and Clear Lake; Fig. 1). These populations and their histories are discussed in Mock and Miller (2005).

Genetic structuring among 5 of the 6 naturally occurring least chub populations, representing 3 of the known locations (Snake Valley and Mona Springs in the Great Salt Lake subbasin and Mills Valley Springs in the Sevier subbasin), was recently reported by Mock and Miller (2005). Their genetic analysis, which included amplified fragment length polymorphism (AFLP) analysis and mitochondrial DNA sequencing, suggested pronounced but temporally shallow genetic structuring among these 3 locations, following patterns of recent and historical hydrogeographic isolation. The most genetically divergent population in this analysis was in Mona Springs, located in the extreme southeastern reach of the Great Salt Lake subbasin, followed by the Mills Valley Springs population in the Sevier subbasin (Fig. 1). The 3 Snake Valley populations (Leland Harris Springs, Gandy Salt Marsh, and Bishop Springs) were genetically similar, consistent with their spatial proximity.

The 6th and southernmost population of least chub, not included in the analyses of Mock and Miller (2005), was discovered in June 2003 at the Clear Lake Waterfowl Management Area, south of Delta, Utah, in the Sevier subbasin (Fig. 1). The Clear Lake Waterfowl Management
Area is a series of dike-created ponds fed by springs. The discovery of this new population was particularly exciting because a large proportion of this species' genetic diversity is at the population level $\left(F_{\mathrm{ST}}=0.52\right.$; Mock and Miller 2005). In this study, we conducted a genetic analysis of the Clear Lake population of least chub and interpret the results within the existing framework of genetic data for the species.

Twenty-two fin clip samples were collected from Clear Lake least chub by Utah Department of Wildlife Resources personnel in August 2004. DNA was extracted from these samples following a "salting-out" protocol based on Sunnucks and Hales (1996). The quality and quantity of extracted DNA was assessed on a $0.7 \%$ agarose gel with appropriate size and concentration standards.

Mitochondrial cytochrome b sequencing was performed following Mock and Miller (2005), with the following exceptions: (a) each $50-\mu \mathrm{L}$ reaction contained $1.5 \mathrm{mM} \mathrm{MgCl}_{2}$; (b) the annealing temperature for PCR was $48^{\circ} \mathrm{C}$; (c) amplicons were purified using Montage PCR spin columns (Millipore, Billerica, MA); (d) sequencing reactions were performed using ET Dye Terminator ddNTPs (Amersham Biosciences, Piscataway, NJ) and contained approximately $50 \mathrm{ng}$ purified PCR product; and (e) sequencing reactions were run on a 5\% Long Ranger polyacrylamide gel using an ABI 377 DNA sequencer (Applied Biosystems, Foster City, CA). Three sequences were obtained from the cytochrome $\mathrm{b}$ gene and used to construct a contiguous sequence of 1068 base pairs (bp) for each of 6 individuals from the Clear Lake population using DNA Star SeqMan software (Lasergene). These sequences were added to

${ }^{1}$ Department of Forest, Range, and Wildland Resources, Utah State University, Logan, UT 84322-5230.

2E-mail: karen.mock@usu.edu 


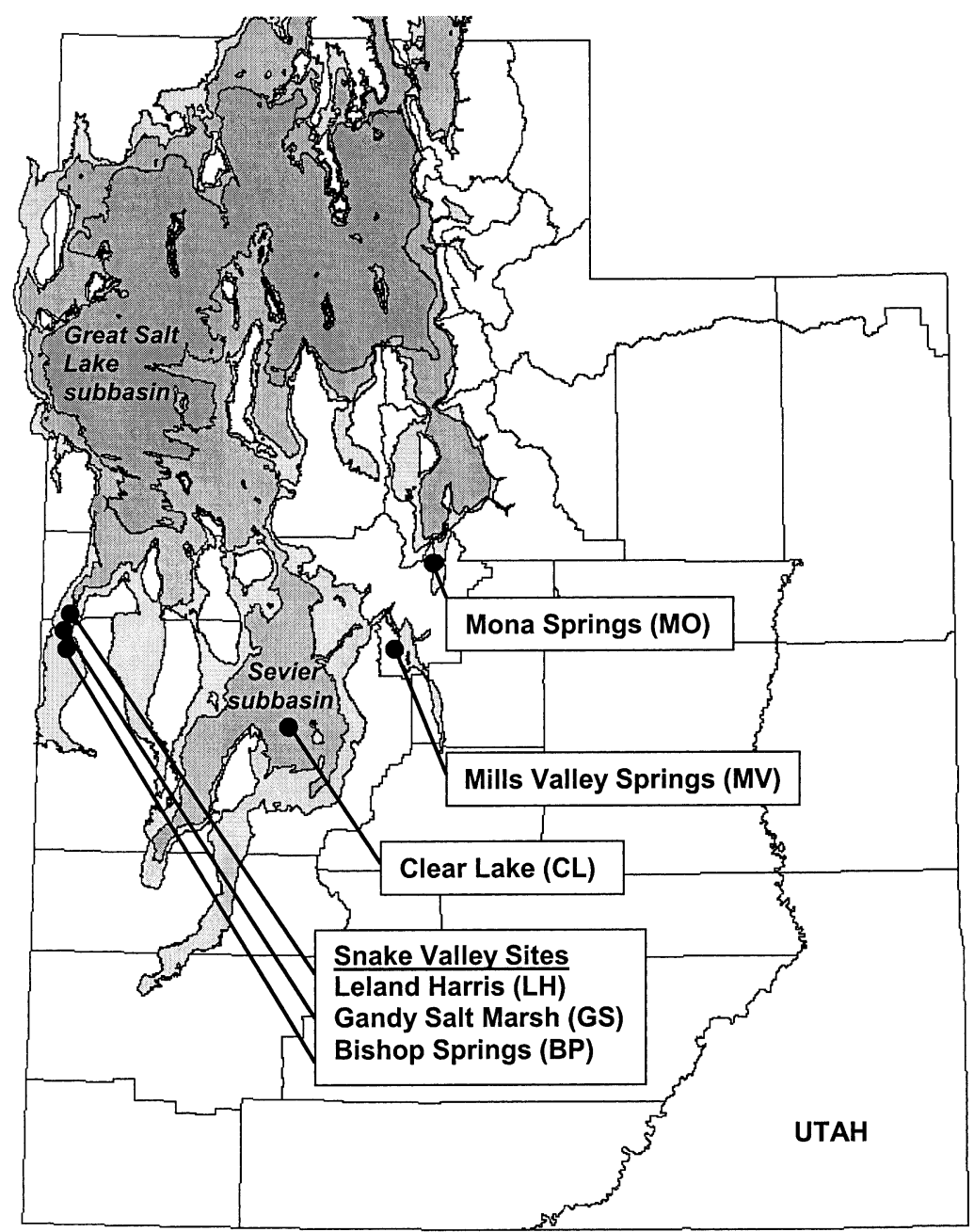

Gilbert Level 11,000 - 10,000 years ago

Provo Level 14,500 - 13,500 years ago

Bonneville Level 16,000 - 14,500 years ago

Fig. 1. Locations of naturally occurring populations of least chub. Maximum levels of the ancient Lakes Bonneville, Gilbert (Great Salt Lake subbasin), and Gunnison (Sevier subbasin) are indicated by shading (map adapted from Currey et al. 1984, modified by Mock and Miller 2005).

the dataset from Mock and Miller (2005; 1101 bp alignment), and a new mitotype network was constructed using TCS 1.18 software (Clement et al. 2000).

Amplified fragment length polymorphism (AFLP) analysis was performed on all 22 Clear Lake least chub samples following protocols described in Mock and Miller (2005). The resulting chromatograms were scored along with previously generated chromatograms from the 5 naturally occurring populations described in Mock and Miller (2005). In order to assure reproducibility between AFLP analytical efforts conducted in different years, 41 of the original DNA samples from Mock and Miller (2005) were included in the AFLP reactions along with the Clear Lake samples, including 15 from Mills Valley Springs, 14 from Bishop Springs, 
TABLE 1. Diversity indices in least chub populations based on (1) amplified fragment length polymorphism (AFLP) analysis of 63 polymorphic loci: percent polymorphic loci $(\% \mathrm{P})$ and estimated unbiased heterozygosity $(\mathrm{H})$; and $(2)$ mitochondrial (mtDNA) sequence diversity (1101 bp cytochrome b).

\begin{tabular}{lcccrc}
\hline Population & $n($ AFLP $)$ & $\% \mathrm{P}$ & $\mathrm{H}$ & $n$ (mtDNA) & Mitotypes \\
\hline Leland Harris Springs & 6 & 47.62 & 0.213 & 5 & 2 \\
Gandy Salt Marsh & 12 & 52.38 & 0.216 & 5 & 2 \\
Bishop Springs & 24 & 53.97 & 0.219 & 5 & 4 \\
Mona Springs & 31 & 39.68 & 0.173 & 17 & 5 \\
Mills Valley Springs & 41 & 42.86 & 0.154 & 5 & 4 \\
Clear Lake & 22 & 49.21 & 0.206 & 6 & 2 \\
\hline
\end{tabular}

and 12 from Mona Springs. Replication of this subset of original samples yielded an error rate of $0.94 \%$, which was judged to be sufficiently low to allow a combined analysis of the previously scored data (Mock and Miller 2005) with the AFLP data produced more recently for the Clear Lake population. Seven of the 70 original AFLP loci did not amplify adequately in the set of 41 replicates and were excluded from further analysis. To assess whether this reduced number of loci influenced the data analysis reported in Mock and Miller (2005), we reanalyzed the original data with only 63 loci. We found that the exclusion of these loci did not change the estimation of $F_{\mathrm{ST}}$, the topology or bootstrap support in UPGMA analysis, or the results of pairwise population exact testing.

Using the 63-locus AFLP profiles from the original Mock and Miller (2005) data (5 populations) and the Clear Lake population (Fig. 1, Table 1), diversity measures (percent polymorphic loci and estimated heterozygosity) were calculated using Tools for Population Genetic Analysis (TFPGA) software (Miller 1997). Additionally, divergence among the 6 populations was assessed using UPGMA cluster analysis, $\theta_{\mathrm{ST}}$ (an estimator of $F_{\mathrm{ST}}$; Weir and Cockerham 1984) and Fisher's exact test (Raymond and Rousset 1995).

Of the 6 individual Clear Lake least chub used for mitochondrial cytochrome b sequencing, 5 were found to have the common ancestral mitotype found in all other least chub populations, and 1 had a mitotype not previously observed in the species (Fig. 2). The new mitotype differed from the common mitotype by a single mutation and reinforced the generally star-like phylogeny described by Mock and Miller (2005) for the species (i.e., a common, widespread haplotype with multiple minor local variants). Such star-like networks are thought to be a signature of a demographic expansion following a bottleneck, possibly reflecting late Pleistocene fluctuations in Lake Bonneville levels (Currey et al.1984, Jarrett and Malde 1987, Currey 1990). The Mona Springs population continues to be an exception to this species-wide pattern, suggesting that it may have a distinct evolutionary history (Mock and Miller 2005). The level of mitotype diversity was similar to that observed in other populations of least chub (Table 1), although sample sizes were too small for rigorous assessment.

The estimates of population-level structuring in the species decreased slightly (albeit nonsignificantly) with the inclusion of the Clear Lake samples. The original samples (using data from 63 loci in all naturally occurring populations) yielded a $\theta_{\text {ST }}$ estimate of 0.4822 (95\% C.I. $0.4057-0.5575)$, while the $\theta_{\text {ST }}$ estimate with Clear Lake included was 0.4395 (95\% C.I. 0.3680-0.5094). The UPGMA analysis including Clear Lake produced a dendrogram linking the Mills Valley Springs and Clear Lake populations with strong bootstrap support. The remainder of the dendrogram topology was unchanged from the analysis of Mock and Miller (2005), although bootstrap support for the node separating the Snake Valley populations from the Sevier River populations increased from $53 \%$ to $62 \%$ (Fig. 3).

Overall AFLP-based estimates of genetic diversity in the species, pooling samples from all populations, were not affected by the inclusion of the Clear Lake population. Overall unbiased estimated heterozygosity was unchanged at 0.31 , and overall percentage of polymorphic loci increased from $88.9 \%$ to $90.5 \%$. Population-level estimates of genetic diversity indicate that the Clear Lake population is similar to other populations of least chub, although diversity indices were slightly lower than those 


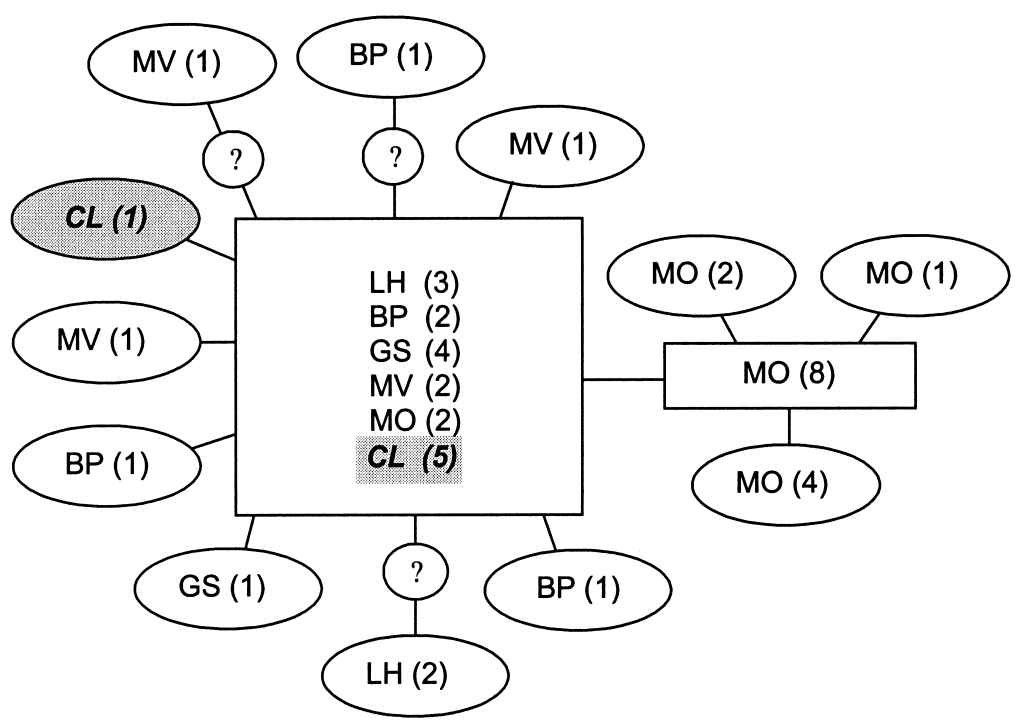

Fig. 2. Mitotype network showing mutational changes among least chub cytochrome b mitotypes. Individuals are designated according to population: Clear Lake (CS, shaded), Mona Springs (MS), Gandy Salt Marsh (GS), Leland Harris Springs (LH), Bishop Springs (BP), and Mills Valley Springs (MV), as described here and in Mock and Miller (2005). Lines represent single mutational changes. Hypothesized, unobserved mitotypes were denoted with "?". The mitotypes with the highest ancestral probabilities are bounded by rectangles. Mitotypes are represented in GenBank accessions AY641413-AY641427 and DQ065820.

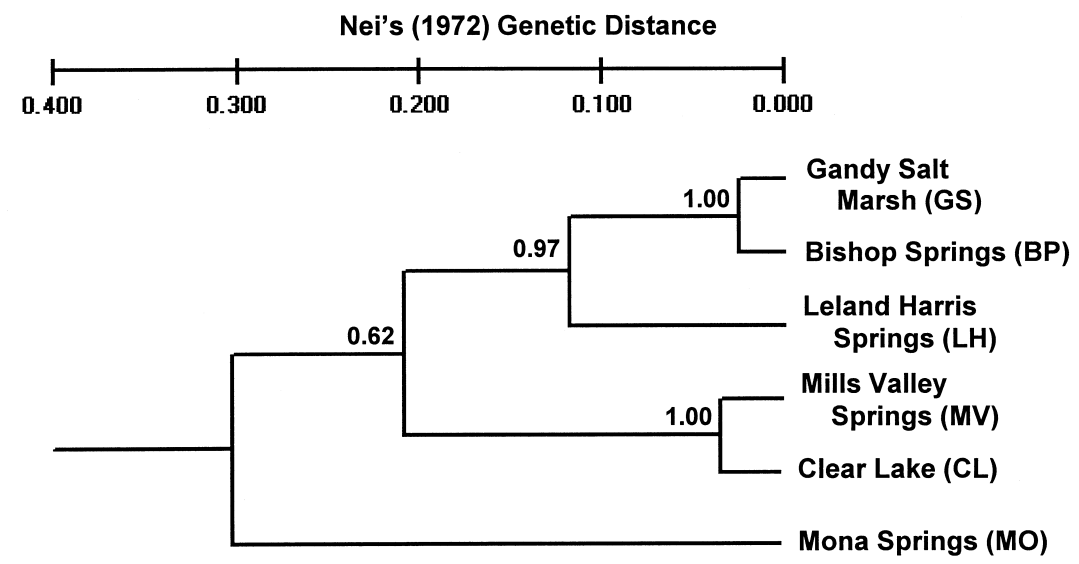

Fig. 3. A UPGMA dendrogram of the extant, naturally occurring least chub populations based on data from 63 polymorphic AFLP loci. Population locations, histories, and previous genetic analyses are described in Mock and Miller 2005. Bootstrap proportions (1000 replicates over loci) are shown at the nodes. 
for the Leland Harris Springs, Gandy Salt Marsh, and Bishop Springs populations (Table 1), and slightly higher than those for either the Mona Springs or Mills Valley Springs populations. The Clear Lake population was also significantly differentiated from the Mills Valley population in terms of AFLP allele frequencies (exact testing $P=0.0001$ ), suggesting that gene flow between these populations is restricted.

The inclusion of the Clear Lake population did not change the species-wide patterns of population genetic diversity and divergence described in Mock and Miller (2005). The Clear Lake population was most similar to the Mills Valley Springs population, consistent with their location in the Sevier subbasin (Fig. 1). However, this population was distinct from, and possibly more diverse than, the Mills Valley Springs population. Given this pattern, we recommend cautious management and monitoring of the Clear Lake Waterfowl Management Area to sustain the extant least chub population there. Further investigation of potential adaptive differences (including habitat differences) between the Mills Valley and Clear Lake populations should be undertaken to determine whether managing these populations as a single unit would be appropriate.

We thank the Utah Division of Wildlife Resources (UDWR) for support of this project and would like to specifically acknowledge the field assistance of the following individuals from the UDWR: C. Bailey, K. Wilson, K. Wheeler, M. Bennion, and C. Schena, as well as Mark Belk (Brigham Young University).

\section{Literature Cited}

Clement, M., D. Posada, and K. Crandall. 2000. TCS: a computer program to estimate gene genealogies. Molecular Ecology 9:1657-1660.
Currey, D.R. 1990. Quaternary paleolakes in the evolution of semidesert basins, with special emphasis on Lake Bonneville and the Great Basin, U.S.A. Paleogeography, Paleoclimatology, Paleoecology 76:189214.

Currey, D.R., G. Atwood, and D.R. Mabey. 1984. Major levels of Great Salt Lake and Lake Bonneville. State of Utah Department of Natural Resources, Utah Geological and Mineral Survey, Map 73, Salt Lake City, UT.

JARRETT, R.D., AND H.E. MALDE. 1987. Palaeodischarge of the late Pleistocene Bonneville flood, Snake River, Idaho, computed from new evidence. Geological Society of America Bulletin 99:126-134.

MiLler, M.P. 1997. Tools for population genetic analysis (TFPGA) 1.3: a Windows program for the analysis of allozyme and molecular population genetic data. Available from: http://bioweb.usu.edu/mpmbio

Mock, K.E., AND M.P. Miller. 2005. Patterns of molecular diversity in naturally occurring and refugial populations of the least chub. Transactions of the American Fisheries Society 134:267-278.

Muck, J. 1999. Least chub candidate conservation. Endangered Species Bulletin: September-October. Available from: http://www.nativefish.or/Articles/least.htm

Page, L.M., AND B.M. Burr. 1991. A field guide to freshwater fishes of North America north of Mexico. Houghton Mifflin, Boston, MA.

Raymond, M.L., AND F. Rousset. 1995. An exact test for population differentiation. Evolution 49:1280-1283.

SigLER, W.F., AND R.R. MiLLER. 1963. Fishes of Utah. Utah State Fish and Game Department, Salt Lake City.

SunnuCKs, P., AND D.F. Hales. 1996. Numerous transposed sequences of mitochondrial cytochrome oxidase I-II in aphids of the genus Sitobion (Hemiptera: Aphididae). Molecular Biology and Evolution 13: $510-523$.

Weir, B.S., and C.C. Cockerham. 1984. Estimating Fstatistics for the analysis of population structure. Evolution 38:1358-1370.

Received 25 August 2005 Accepted 8 June 2006 